\title{
METODOLOGIA PARA EXPRESSÃO DA GLICOPROTEÍNA S1 DO VÍRUS DA BRONQUITE INFECCIOSA DAS GALINHAS EM SISTEMAS PROCARIOTO E EUCARIOTO
}

\section{RESUMO}

\begin{abstract}
A bronquite infecciosa das galinhas (IB) é uma enfermidade altamente contagiosa que acomete aves de todas as idades e causa grandes prejuízos na avicultura. O trabalho descreve uma metodologia para expressão da glicoproteína S1 do vírus da bronquite infecciosa das galinhas (IBV) em Pichia pastoris e Escherichia coli. Para P. pastoris o gene foi amplificado por RT-PCR, com posterior clonagem e expressão no vetor pPICZ $\alpha$ B. Para E. coli, foi elaborado o gene sintético a partir de uma sequência consenso de amostras de campo nacionais e internacionais, clonado e expresso no vetor $p A E$. Após indução dos clones, a proteína S1 foi identificada pelas técnicas de Dot blotting e Western blotting. A proteína expressa apresentou reatividade frente a soros de aves positivas para IBV, evidenciando sua antigenicidade.
\end{abstract}

Palavras-chave: Bronquite Infecciosa das galinhas. Glicoproteína S1. Proteína recombinante. Pichia pastoris. Escherichia coli. 
A bronquite infecciosa das galinhas (IB) é uma enfermidade altamente contagiosa e de curto período de incubação, causada por um vírus da família Coronaviridae, gênero Coronavirus (CAVANAGH, 2007). Aves infectadas apresentam diminuição do desempenho, perda de peso e refugagem. Infecções bacterianas secundárias levam a grandes perdas econômicas por condenação de carcaças, principalmente devido à aerossaculite (CAVANAGH, 2007; MENDONÇA et al., 2009).

O IBV possui genoma RNA de fita simples e codifica quatro proteínas estruturais importantes: N (proteína do nucleocapsídeo), S (proteína de superfície), E (proteína do envelope) e M (proteína da membrana). A glicoproteína S possui segmentos S1 e S2, sendo que a porção S1 fica exposta no envelope viral, o que a torna um importante indutor da produção de anticorpos neutralizantes e, consequentemente, o principal alvo para o sistema imune do hospedeiro (CAVANAGH, 1983, 2007). Devido a sua imunogenicidade, a proteína S1 pode ser um antígeno adequado para utilização em diagnóstico sorológico e monitoramento vacinal das aves (IGNJATOVIC; GALLI, 1994; ZOU et al., 2015).

A levedura Pichia pastoris é um microrganismo eucarioto e vem sendo utilizado como sistema de expressão devido a sua capacidade de processar a maioria das modificações póstraducionais. Dentre essas, processamento proteolítico e glicosilação, o que pode resultar em proteínas com características antigênicas originais conservadas, permitindo aplicação em ensaios diagnósticos ou mesmo em vacinas de subunidade (CEREGHINO; CREGG, 2000). A expressão de proteínas recombinantes em procariotos, até o momento, tem maior utilização (LUGOVSKAYA et al., 2006), embora a maioria não possua sistema de endomembranas e não realize modificações pós-traducionais, o que pode impedir o correto processamento de proteínas heterólogas de eucariotos (CREGG, 1985).

Visando obter a proteína S1 do IBV, este trabalho relata a clonagem e a expressão do gene que codifica a proteína de superfície S1 do IBV em Pichia pastoris e em Escherichia coli.

Inicialmente foi realizada a expressão da proteína S1 a partir de sequência gênica de um isolado brasileiro do IBV com perfil semelhante (dados não mostrados) à cepa Massachussets (M41CNPSA - EMBRAPA - Concórdia, SC) em P. pastoris. O isolado M41CNPSA foi propagado em ovos embrionados SPF (Specific Pathogen Free) com nove dias 
de incubação na cavidade corioalantóide e o RNA foi extraído do líquido corioalantóide com a utilização de Trizol $^{\circledR}$ LS Reagent (Invitrogen ${ }^{\text {TM }}$ ).

A partir do RNA foi obtido cDNA por transcrição reversa (RT), usando oligonucleotídeo randômico para, em seguida, ser amplificada pela reação em cadeia da polimerase (PCR) toda a Open Reading Frame (orf) referente ao gene da glicoproteína S1. Com base na sequência do gene da proteína S1 da cepa M41 do IBV ("GenBank" n de acesso - M21883) foram desenhados os primers forward e reverse para a completa amplificação do gene. Sítios de clivagem para as enzimas de restrição EcoRI e Kpnl foram introduzidos no primer foward (5'- CGGAATTCCTGCTTTGTATGACAGT-3') e reverse (5'- CCGGTACCTTAATGTAAAACTGG- 3'), respectivamente.

A PCR foi realizada em uma solução com volume final de $50 \mu \mathrm{l}$, contendo 0,2 mM de dNTPs, 2 unidades de Taq DNA Polimerase, $\mathrm{MgCl}_{2}$ a 3,5 mM, Buffer $1 \mathrm{X}, 5 \mathrm{M}$ de Betaine e 0,2 pmol de cada primer. A essa solução foi adicionado $3 \mu l$ de cDNA, submetendo a uma desnaturação inicial de $95{ }^{\circ} \mathrm{C}$ por 7 minutos, $70{ }^{\circ} \mathrm{C}$ por 1 minuto, 45 ciclos de $94{ }^{\circ} \mathrm{C}$ por 1 minuto, $50{ }^{\circ} \mathrm{C}$ por 1 minuto e $72{ }^{\circ} \mathrm{C}$ por 4 minutos, com extensão final de $72{ }^{\circ} \mathrm{C}$ por 10 minutos. O fragmento esperado de $1.540 \mathrm{pb}$ foi obtido e o produto amplificado foi purificado com GFX PCR DNA e Gel Band Purification Kit (GE Healthcare, USA), de acordo com as especificações do fabricante.

Para expressão em $P$. pastoris foi utilizado o vetor de expressão pPICZaB. O plasmídeo pPICZ $\alpha \mathrm{B}$ e o produto da PCR purificado foram digeridos com as enzimas Kpnl e EcoRI e ligados com T4 DNA - ligase (Invitrogen). O produto desta reação (vetor pPICZaB/S1) foi utilizado para transformar, por choque térmico, células competentes da cepa TOP10F de $E$. coli, resultando em muitas colônias, sendo sete confirmadas por análise de restrição como recombinantes. Os transformantes foram selecionados em placas com meio Luria Bertani (LB) (1\% de triptona, $0,5 \%$ de extrato de levedura, $0,5 \%$ de $\mathrm{NaCl}$ e $2 \%$ de Ágar) contendo 25 $\mu \mathrm{g} \cdot \mathrm{mL}^{-1}$ de zeocina.

O recombinante $\mathrm{pPICZ} \alpha \mathrm{B} / \mathrm{S} 1$ foi propagado em $E$. coli, purificado, linearizado com a enzima Pmel (New England Biolabs) e precipitado. A cepa $\mathrm{KM} 71 \mathrm{H}$ fenótipo $\mathrm{Mut}^{\mathrm{S}}$ de $P$. pastoris foi utilizada para a expressão da glicoproteína S1. Células KM71H foram cultivadas em meio YPD 
(extrato de levedura 1\%, peptona 2\% e D-glucose $2 \%$ ) por 18 horas em agitador orbital a 28 ${ }^{\circ} \mathrm{C}$ até a densidade óptica a $600 \mathrm{~nm}\left(\mathrm{OD}_{600}\right)$ de aproximadamente 1,3. $\mathrm{KM} 71 \mathrm{H}$ competentes foram preparadas e transformadas por eletroporação (25 F, 200, 2 kV) com $10 \mu \mathrm{g}$ de pPICZaB/S1 linearizado. Após uma hora da transformação, 100 e $200 \mu \mathrm{L}$ do total de $1 \mathrm{~mL}$ que foi ressuspendido em $1 \mathrm{M}$ de sorbitol, para melhor recuperação das células, foram plaqueados em meio YPDS sólido (meio YPD com $1 \mathrm{M}$ sorbitol e 2\% Agar). Muitas colônias foram observadas após três dias de cultivo em YPDS contendo $100 \mu \mathrm{g} / \mathrm{mL}$ ou $500 \mu \mathrm{g} / \mathrm{mL}$ de zeocina e foram repicadas para uma nova placa contendo YPD. Posteriormente, as colônias foram repicadas em meio BMGY (1\% de extrato de levedura, $2 \%$ peptona, $1,34 \%$ de YNB (Yeast Nitrogen Base), $4 \times 10^{-5} \%$ de biotina, 1\% de glicerol e $100 \mathrm{mM}$ Tampão Fosfato de Potássio, $\mathrm{pH} 6$,0) por 24 horas e a seguir incubadas a $28^{\circ} \mathrm{C}$ por seis dias, sendo adicionado 0,5\% de metanol absoluto a cada 24 horas no topo das placas para a indução da expressão (meio BMMY). Células $\mathrm{KM} 71 \mathrm{H}$ não transformadas foram também cultivadas como controle negativo.

No final da indução foi realizada a técnica de Colony blotting. As colônias foram transferidas para membranas de nitrocelulose Hybond ${ }^{\mathrm{TM}} \mathrm{ECL}$ por 3 horas a $28^{\circ} \mathrm{C}$ e bloqueadas com leite

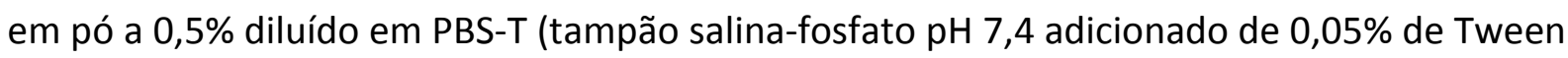
20) sob agitação leve durante 1 hora. Após quatro lavagens com PBS-T, as membranas foram incubadas com anticorpo anti-histidina conjugado (Anti-6xHIS HRP - Invitrogen) por 1 hora. As colônias recombinantes foram detectadas por revelação com SIGMA FAST ${ }^{T m}$ DAB (SigmaAldrich), seguindo as instruções do fabricante.

Após o teste de expressão em placa, nove colônias de $P$. pastoris recombinantes foram selecionadas, sendo sete confirmadas na PCR para amplificação do gene S1. O clone recombinante que demonstrou uma maior expressão no colony blot foi selecionado para indução da expressão em meio líquido. Uma colônia do clone recombinante escolhido foi inoculada em balão aletado de $500 \mathrm{~mL}$ contendo $100 \mathrm{~mL}$ de meio BMGY e deixada em agitação orbital de $250 \mathrm{rpm}$ a uma temperatura de $28^{\circ} \mathrm{C}$ por 24 horas. Após atingir uma $\mathrm{OD}_{600}$ de 20-30, o cultivo foi centrifugado e as células ressuspendidas em BMMY, em volume cinco vezes menor. A indução da expressão foi realizada a $28^{\circ} \mathrm{C}$ com agitação de $250 \mathrm{rpm}$ 
por seis dias. A cada 24 horas, 0,5\% de metanol (v/v) foi adicionado e o sobrenadante coletado para detecção da proteína S1.

A seguir, as leveduras sedimentadas por centrifugação foram submetidas à extração de proteína celular total, uma vez que a proteína poderia estar retida na célula. Para tal, as células foram ressuspendidas em tampão de lise $(50 \mathrm{mM}$ fosfato de sódio monobásico, $\mathrm{pH}$ 7,4, $1 \mathrm{mM}$ EDTA, 5\% glicerol, $1 \mathrm{mM}$ fluoreto de fenilmetilsulfonila-PMSF) e igual volume de "glass beads acid-washed 425-600 $\mu \mathrm{M}$ " (Sigma-Aldrich Corp., St. Louis, USA). Seguiu-se centrifugação a $12.000 \mathrm{~g}$, por 10 minutos, a $4{ }^{\circ} \mathrm{C}$, e foi demonstrada a presença da proteína S1 pela técnica de Dot blotting.

A proteína expressa foi detectada após lise do pellet celular, utilizando-se anticorpos produzidos em galinhas imunizadas com a cepa M41 de IBV (Figura 1). A expressão foi detectada a partir de 48 horas tendo sido observado maior intensidade de reação no Dot blotting após 96 horas de indução, indicando ser esse o melhor tempo para a expressão da proteína.

Diluição 1:50 Diluição 1:100

S1 $\quad$ C- $\quad$ S1 $\quad$ C-

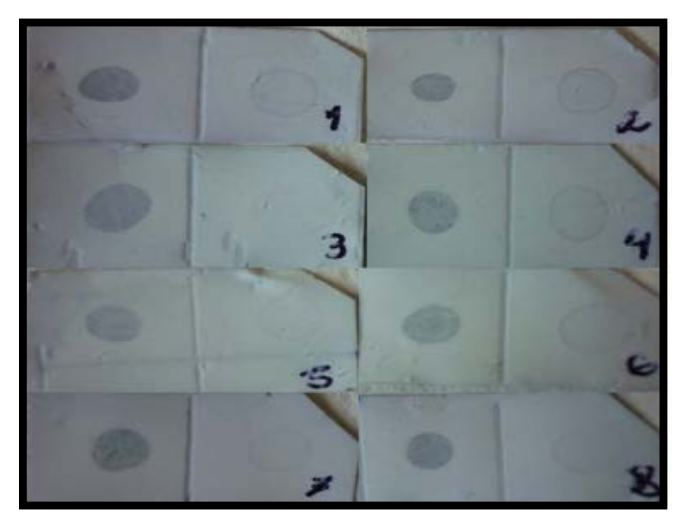

Figura 1 - Dot blotting para caracterização da glicoproteína S1 recombinante expressa em Pichia pastoris após 96 horas de indução, frente a diluições (1:50 e 1:100) de soros de aves imunizadas com a cepa M41 de IBV (18).

Para a expressão da S1 em sistema procarioto foi construído um gene sintético baseado em sequências consenso entre amostras de campo nacionais (provenientes da Embrapa Suínos e Aves) e internacionais (depositadas no GenBank), utilizando-se o programa Vector NTI 
(Invitrogen ${ }^{\circledR}$ ). Ao DNA sintético foram adicionados sítios de restrição para as enzimas $X h o l$ e $K p n l$, visando a clonagem direcional no vetor de expressão $p A E$ de $E$. coli. O gene foi sintetizado pela empresa Epoch Biolabs (USA). O gene sintético clonado no vetor pUC19 foi liberado mediante digestão com Xhol e Kpnl e purificado do gel de agarose usando GFX PCR DNA e Gel Band Purification Kit. $O$ gene foi então inserido no vetor $p A E$ previamente digerido com Xhol e Kpnl, usando T4 DNA-ligase. O produto resultante da ligação foi utilizado para transformar, mediante choque térmico, a cepa TOP10F de E. coli.

Os transformantes foram selecionados após cultivo em placas com meio Luria Bertani suplementado com $100 \mu \mathrm{g} \cdot \mathrm{mL}^{-1}$ de ampicilina. Colônias transformantes foram selecionadas para extração do plasmídeo. O plasmídeo recombinante $p A E / S 1$ confirmado por análise de restrição (dados não mostrados) foi utilizado para transformar as cepas de expressão pLysS e Star. Colônias recombinantes, produto das transformações, foram repicadas para meio LB contendo ampicilina para Star $\left(100 \mu \mathrm{g} \cdot \mathrm{mL}^{-1}\right)$ e cloranfenicol para pLySs (50 $\mu \mathrm{g} \cdot \mathrm{mL}^{-1}$ ) em agitador orbital a $200 \mathrm{rpm}$ a $37{ }^{\circ} \mathrm{C}$ por 16 horas. Após esse período, o pré-inóculo foi transferido para um novo meio LB contendo os antibióticos nas mesmas concentrações. Após atingir $O D_{600}$ próximo a 0,8 a expressão da proteína recombinante foi induzida pela adição de IPTG (isopropil ß-D-1-tiogalactopiranosídeo) na concentração final de 0,3 mM. Após incubação por mais 3 horas a $37{ }^{\circ} \mathrm{C}$ sob agitação de $200 \mathrm{rpm}$, as culturas foram submetidas ao processo de centrifugação a $10.000 \mathrm{rpm}$, por 10 minutos a $4{ }^{\circ} \mathrm{C}$ para obtenção das células contendo a proteína.

As cepas transformadas foram analisadas por eletroforese em gel de poliacrilamida (SDSPAGE) e foi detectada a proteína de aproximadamente $57 \mathrm{kDa}$, confirmando o tamanho esperado. A expressão da S1 foi confirmada pela técnica de Western blotting (Figura 2). 


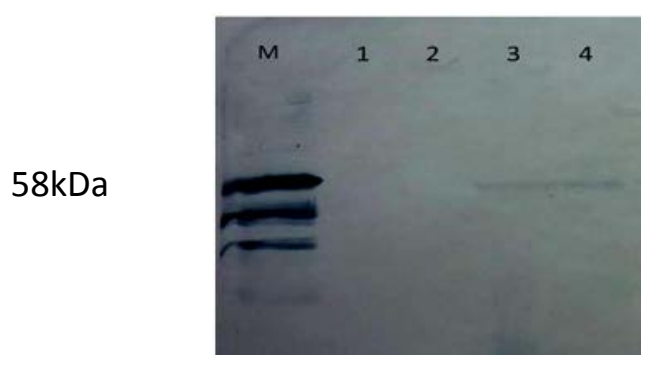

Figura 2 - Western blotting de clones recombinantes de $E$. coli após 3 horas de indução de expressão com IPTG utilizando anticorpo monoclonal Anti-6xHIS. M = Proteína M recombinante com 58 kDa (marcador), 1- Controle negativo E. coli Star, 2- Controle negativo E. coli LySS, 3- Cultivo E. coli Star expressando a proteína S1, 4Cultivo $E$. coli $p L y S s$ expressando a proteína $\mathrm{S} 1$.

A produção heteróloga de antígenos virais a partir da expressão de genes clonados constitui um importante método de preparo rápido de grandes quantidades de antígenos altamente purificados que podem ser utilizados como reagentes de diagnóstico. Neste estudo foi descrito a clonagem e a expressão da glicoproteína S1 do envelope do IBV em sistema procarioto e eucarioto.

A presença da proteína S1 foi verificada no extrato celular da levedura $P$. pastoris, contudo, não foi possível detectar a S1 nos sobrenadantes de cultivo, evidenciando dificuldade da levedura em realizar a secreção da glicoproteína. Essa dificuldade também foi relatada na tentativa de produção da proteína S1 recombinante do vírus da síndrome respiratória aguda severa (SARS), um coronavírus humano, utilizando pPIC9K como vetor (LU et al., 2006) e, mais recentemente, na tentativa de expressar a S1 do IBV em linhagem GS115 de $P$. pastoris, cujo fenótipo é do tipo Mut $^{+}$(GONÇALVES et al., 2010). O processo de expressão da proteína recombinante em $E$. coli foi mais rápido e houve maior facilidade da recuperação da proteína da célula, quando comparado ao sistema em P. pastoris.

A E. coli tem sido bastante usada como sistema de expressão de proteínas recombinantes, por ser um organismo geneticamente bem conhecido, por apresentar uma rápida e alta taxa de multiplicação, fácil cultivo e baixo custo, porém a proteína que resulta da expressão nesse sistema não sofre glicosilação, perdendo assim sua conformação original (CREGG et al., 1985). As proteínas em E. coli podem ser expressas no espaço intracelular, de forma 
solúvel ou formando corpos de inclusão, que são agregados de proteínas insolúveis ou secretadas para o meio extracelular ou espaço periplasmático (CREGG et al., 1985).

Embora tenhamos utilizado duas cepas de E. coli (BL21 Star e pLySs), a proteína de 57 kDa foi detectada somente na fração intracelular insolúvel, e não no meio extracelular, nem na fração intracelular solúvel, conforme verificado no Dot blotting com ambas as frações (dados não mostrados). Isso indica que a proteína foi produzida principalmente na forma de corpos de inclusão, podendo estar presente no meio extracelular solúvel ou na fração intracelular solúvel em níveis abaixo do limite de sensibilidade do SDS-PAGE. A expressão heteróloga em P. pastoris pode ser intracelular ou secretada (CEREGHINO; CREGG, 2000). Para ser secretada é necessária a presença de uma sequência sinalizadora de secreção na proteína expressa (peptídeo sinal), sendo que, para o presente estudo, foi utilizado o $\alpha$-Factor. Uma vantagem da $P$. pastoris é a secreção em baixo nível de proteínas homólogas estando presente no meio essencialmente a proteína heteróloga. Contudo, a proteína recombinante S1 não foi detectada no meio extracelular, somente com a lise do pellet foi evidenciada a proteína resultante pela técnica de Dot Blot.

A proteína S1 pode ser expressa em sistema procarioto e eucarioto. Futuramente as proteínas S1 expressas em $P$. pastoris e $E$. coli serão caracterizadas e avaliadas para uso em testes de imunodiagnóstico. 


\title{
METHODOLOGY FOR THE EXPRESSION OF AVIAN INFECTIOUS BRONCHITIS VIRUS S1 GLYCOPROTEIN IN PROKARYOTE AND EUKARYOTE SYSTEMS
}

\begin{abstract}
nfectious bronchitis (IB) is a highly contagious disease that affects birds of all ages and causes great losses in poultry. The paper describes a method for the expression of the glycoprotein S1 of infectious bronchitis virus (IBV) in Pichia pastoris and Escherichia coli. For the expression using $P$. pastoris, the gene was amplified by RT-PCR with subsequent cloning and expression in the PPICZ $\alpha$ B vector. For the expression using $E$. coli, the gene was synthesized from a consensus sequence of national and international samples, being cloned and expressed in the $P A E$ vector. After induction of the clones, $\mathrm{S} 1$ protein was identified by the Dot blotting and Western blotting techniques. The expressed protein showed positive reactivity against IBV positive poultry sera showing its antigenicity.
\end{abstract}

Keywords: Avian Infectious Bronchitis. S1 glycoprotein. Recombinant protein. Pichia pastoris. Escherichia coli.

\section{METODOLOGÍA DE MANIFESTACIÓN DE GLICOPROTEÍNA S1 DE BRONQUITIS INFECCIOSA DE POLLOS EN SISTEMAS PROCARIOTAS Y EUCARIOTAS}

\section{RESUMEN}

a bronquitis infecciosa (IB) es una enfermedad altamente contagiosa que afecta a las aves de todas las edades y causa grandes pérdidas en las aves de corral. El documento describe un método para la expresión de la glicoproteína S1 del virus de la bronquitis infecciosa (IBV) en Pichia pastoris y Escherichia coli. Para P. pastoris el gen se amplificó por RT-PCR con la posterior clonación y expresión del vector pPICZaB. Para E. coli, y fue formulada gen sintético a partir de una secuencia de consenso de muestras nacionales e internacionales de campo, clonado y expresado en el vector $p A E$. Después de la inducción de los clones, la proteína S1 fue identificada por técnicas de Dot y Western blotting. La proteína expresada mostró reactividad frente a sueros positivos de las aves a IBV, mostrando su antigenicidad.

Palabras clave: Bronquitis infecciosa en pollos. Glicoproteína S1. Proteína recombinante. Pichia pastoris. Escherichia coli. 


\section{REFERÊNCIAS}

CAVANAGH, D. Coronavirus IBV: structural characterization of the spike protein. Journal of General Virology, v. 64, p. 2577-2583, 1983.

CAVANAGH, D. Coronavirus avian infectious bronchitis virus. Veterinary Research, v. 38, p. 281-297, 2007.

CEREGHINO, J. L.; CREGG, J. M. Heterologous protein expression in the methylotrophic yeast Pichia pastoris. FEMS Microbiology Reviews, p. 45-66, 2000.

CREGG, J. M.; BARRINGER, K. J.; HESSLER, A. Y.; MADDEN, K. R. Pichia pastoris as a host system for transformations. Molecular and Cellular Biology, v. 5, p. 3376-3385, 1985.

GONÇALVES, M.; GIBERTONI, A.; MONTASSIER, M.; FERNANDES, C.; MONTASSIER, $\mathrm{H}$. Clonagem e expressão do gene da glicoproteína S1 do vírus da bronquite infecciosa das galinhas em Pichia pastoris. Arquivos do Instituto Biológico, v. 77, p. 609-615, 2010.

IGNJATOVIC, J.; GALLI, L. The S1 glycoprotein but not the N or M proteins of avian infectious bronchitis virus induces protection in vaccinated chickens. Archives of Virology, v. 138, p. 117-134, 1994.

LU, H.; YANG, G.; FEI, X.; GUO, H.; TAN, Y.; CHEN, H.; GUO, A. Modification of SARS-CoV S1 gene render expression in Pichia pastoris. Virus Genes, v. 33, p. 329-335, 2006.

LUGOVSKAYA, N.; SCHERBAKOV, A.; YAKOVLEVA, A.; TSYVANYUK, M.; MUDRAK, N.; DRYGIN, V.; BORISOV, A. Detection of antibodies to avian infectious bronchitis virus by a recombinant nucleocapsid protein-basead enzyme-linked immunosorbent assay. Journal of Virological Methods, v. 135, p. 292-296, 2006.

MENDONÇA, J. F. P.; MARTINS, N. R. S.; CARVALHO, L. B.; SÁ, M. E. P.; MELO, C. B. Bronquite infecciosa das galinhas: conhecimentos atuais, cepas e vacinas no Brasil. Ciência Rural, v. 39, p. 2559-2566, 2009.

ZOU, N., WANG, F., DUAN, Z., XIA, J., WEN, X., YAN, Q., LIU, P., CAO, S., HUANG, Y. Development and characterization of neutralizing monoclonal antibodies against the S1 subunit protein of QX-like avian infectious bronchitis virus strain Sczy3. Monoclonal Antibodies Immunodiagnosis Immunotherapy, v. 34, p. 17-24, 2015. 